\title{
Abnormal populations and functions of natural killer cells in patients with myelodysplastic syndromes
}

\author{
WEI ZHANG ${ }^{*}$, XINYAN XIE*, HUIJING MI ${ }^{*}$, JINWAN SUN, SHAOXUE DING, \\ LIJUAN LI, HUI LIU, HUAQUAN WANG, RONG FU and ZONGHONG SHAO \\ Department of Hematology, General Hospital of Tianjin Medical University, Heping, Tianjin 300052, P.R. China
}

Received March 13, 2017; Accepted December 5, 2017

DOI: $10.3892 / \mathrm{ol} .2018 .8062$

\begin{abstract}
Myelodysplastic syndromes (MDS) are clonal stem cell disorders characterized by ineffective hematopoiesis that lead to leukemia. Disorders of the immune system serve important functions in the pathophysiology and progression of this disease. Different levels or mechanisms of natural killer (NK) cells in patients with MDS have been measured in previous studies, making it challenging to understand the pathogenesis of NK cytotoxicity. The present study investigated the frequency of NK cell-mediated antibody-dependent cellular cytotoxicity and explored the function of NK cells by their activating receptors, inhibition signals, degranulation and cytotoxicity factors. In the present study, levels of cluster of differentiation (CD) $3 \mathrm{CD}^{-} 6^{+} \mathrm{NK}$ cells, CD16 ${ }^{+}$-expressing NK cells and subset CD56 ${ }^{\mathrm{dim}} \mathrm{NK}$ cells were decreased in the peripheral blood of patients with MDS. Altered expression of NK protein 44, NK group 2 member D, killer cell immunoglobulin-like receptor 2DL1 (KIR2DL1) and KIR2DL3 on NK cell effector signaling pathways may trigger tumor cell lysis in patients with MDS. The weak cellular adhesion and decreased cytotoxicity of NK cells may lead to ineffective antitumor activity in MDS. These observations suggested that NK cells may serve as immunological determinants in MDS and may permit the development of NK cell-based immunotherapy for the treatment of patients with MDS.
\end{abstract}

\section{Introduction}

Myelodysplastic syndromes (MDS) are clonal stem cell disorders characterized by dysplastic changes in multiple hematopoietic lineages and ineffective hematopoiesis, which

Correspondence to: Dr Zonghong Shao, Department of Hematology, General Hospital of Tianjin Medical University, 154 Anshan Road, Heping, Tianjin 300052, P.R. China

E-mail: shaozonghong@sina.com

*Contributed equally

Key words: myelodysplastic syndromes, natural killer cells, major histocompatibility complex class I, perforin, granzymes lead to acute myeloid leukemia (AML). Multiple factors have been implicated in the pathogenesis of MDS, including cytogenetic changes and molecular abnormalities, such as gene mutations and epigenetic changes, as well as disturbances in cellular immunity and microenvironment $(1,2)$. Disorder of the immune system serves an important function in the pathophysiology of MDS, and expansion of different $\mathrm{T}$ cell subpopulations may occur at distinct disease stages, suggesting that progression of MDS may be facilitated by immune suppression $(3,4)$.

Natural killer (NK) cells are large granular lymphocytes that function as a component of the innate immune defense system. The functions of NK cells depend on the absolute sum of their simultaneous activation and inhibition signals. For example, a cluster of differentiation (CD)16-mediated activation signal may lead to antibody-dependent cellular cytotoxicity (ADCC) by degranulation- and perforin-dependent target cell lysis, and this NK-mediated ADCC is a dominant component of effective antitumor activity (5). Different levels or mechanisms of NK cells in patients with MDS have been measured in previous studies using different approaches to analyze the NK cells, making it challenging to understand the pathogenesis of NK cytotoxicity (6-8). Therefore, the present study investigated populations of NK cells and examined their functions by activating receptors, inhibition signals and cytotoxicity factors in patients with MDS to determine the function of NK cells as immunological determinants in MDS.

\section{Patients and methods}

Patients and controls. Peripheral blood samples were obtained from 35 patients with MDS, 16 patients with AML and 22 healthy donors referred to the Department of Hematology at General Hospital of Tianjin Medical University (Tianjin, China) from June 2012 to September 2017, following the provision of written informed consent in accordance with the Declaration of Helsinki. The present study was approved by the Tianjin Medical University Institutional Review Board (Tianjin, China). The median age of the patients with MDS was 71 years (range, 40-83 years), and 18 were male and 17 were female. The median age of the patients with AML was 56 years (range, 30-69 years), and 9 were male and 7 were female. The median age of the healthy donors was 30 years (range, 23-60 years), and 12 of them were male and 10 were 
female. According to World Health Organization criteria (9), the patients were classified as refractory anemia, refractory anemia with ring sideroblasts, refractory cytopenias with multi-lineage dysplasia or refractory anemia with excess blasts. Based on the International Prognostic Scoring System (IPSS) the patients were classified in distinct categories as low, intermediate and high risk (10). The characteristics of the patients are presented in Table I.

Measurement of NK cells and NK-like T (NKT) cells from the peripheral blood. NK cells $\left(\mathrm{CD} 3{ }^{-} \mathrm{CD} 56^{+} / \mathrm{CD} 16^{+}\right)$and $\mathrm{NKT}$ cells $\left(\mathrm{CD} 6^{+} \mathrm{CD}^{+}\right)$from fresh samples were identified by single-platform flow cytometric analysis. The NK cell marker antibodies included in the analysis were phycoerythrin (PE)-conjugates of anti-CD158a (cat. no. 556063; 1:10), anti-CD158b(cat.no.559785;1:10), anti-NKG2D(cat.no.561815; 1:10), anti-NKp44 (cat. no. 558563; 1:10) and anti-CD 226 (cat. no. 559789; 1:10), as well as CD56-allophycocyanin (cat. no. 555518; 1:10), CD16-fluorescein isothiocyanate (cat. no. 555406; 1:10) and CD3-peridinin chlorophyll protein complex (cat. no. 552851; 1:10), all of which were obtained from BD Biosciences (Franklin Lakes or San Jose, USA). In a volume of $100 \mu \mathrm{l}$, whole blood was immunostained with $10 \mu \mathrm{l}$ aforementioned antibodies at $4^{\circ} \mathrm{C}$ for $30 \mathrm{~min}$, and red blood cells in the sample were lysed with $1 \mathrm{ml} 1 \mathrm{X}$ FACS $^{\mathrm{TM}}$ lysing solution (BD Biosciences) for $8 \mathrm{~min}$ at room temperature. Then the red blood cell samples were centrifuged at $500 \mathrm{x} \mathrm{g}$ for $5 \mathrm{~min}$ at room temperature and decant the supernatant. The peripheral blood mononuclear cells (PBMNCs) left were washed twice with PBS prior to examination. A minimum of 50,000 cells were examined by flow cytometry per sample. Each specimen was investigated using a FACS-Calibur (BD Biosciences) or a DxFLEX flow cytometer (Beckman Coulter, Inc., Brea, CA, USA) and was analyzed using the CellQuest 3.1 software (BD Biosciences) or the CytExpert 1.0 software (Beckman Coulter, Inc.), respectively.

Measurement of the function of $\mathrm{NK}$ cells. NK cells from fresh samples were labeled as aforementioned. The NK cell receptors included in the analysis were phycoerythrin (PE)-conjugates of anti-CD158a (cat. no. 556063; 1:10), anti-CD158b (cat. no. 559785; 1:10), anti-NKG2D (cat. no. $561815 ; 1: 10$ ), anti-NKp44 (cat. no. 558563; 1:10) and anti-CD 226 (cat. no. 559789; 1:10), all of which were obtained from BD Biosciences (San Jose, USA). PE-conjugated anti-CD107a (cat. no. 130095515; 1:10) was obtained from Miltenyi Biotech (Bergisch Gladbach, Germany). The inhibitory and activating receptors on the cell membranes were stained with $10 \mu \mathrm{l}$ appropriate monoclonal antibodies $(\mathrm{mAb})$ in a $100 \mu \mathrm{l}$ volume at $4^{\circ} \mathrm{C}$ for $30 \mathrm{~min}$. Washed twice with PBS before examination. In order to analyze the cytoplasmic proteins, perforin and granzyme $\mathrm{B}$, the cells were mixed with $1.0 \mathrm{ml} 1 \mathrm{X}$ FACS ${ }^{\mathrm{TM}}$ permeabilizing solution 2 (BD Biosciences) for $10 \mathrm{~min}$. The suspensions were washed with PBS containing $0.1 \%$ sodium azide prior to being stained with the perforin or granzyme B mAbs at room temperature for $30 \mathrm{~min}$ in the dark. Both washed twice with PBS before examination. PE-Perforin (cat. 556437) and PE-Granzyme B (cat. 561142) were obtained from BD Biosciences (San Jose, USA). The inhibitory receptors were identified as CD158a and
Table I. Characteristics of the patients with MDS

Characteristic

Sex

Male 18

Female

WHO subtypes

Refractory anemia

Refractory anemia with ring sideroblasts

Refractory cytopenias with multi-lineage dysplasia $\quad 12$

Refractory anemia with excess blasts

IPSS

Low

Intermediate 1

Intermediate 2

High

MDS, myelodysplastic syndrome; WHO, World Health Organization; IPSS, International Prognostic Scoring System.

Table II. Primers used for reverse transcription-quantitative polymerase chain reaction.

\begin{tabular}{ll}
\hline Target gene & \multicolumn{1}{c}{ Primer sequences } \\
\hline Perforin & \\
Forward & 5'-GAGGAGAAGAAGAAGAAGCACAA-3' \\
Reverse & 5'-AGGGGTTCCAGGGTGTAGTC-3' \\
Granzyme B & \\
Forward & 5'-CCAGCAGTTTATCCCTGTGAA-3' \\
Reverse & 5'-CACCTCTTGTAGTGTGTGTGAGTG-3' \\
NKP44 & \\
Forward & 5'-TCCAAGGCTCAGGTACTTCAAAG-3' \\
Reverse & 5'-GGGCGGGTACTGGCATCT-3' \\
NKG2D & \\
Forward & 5'-TCCATTCTCTCACCCAACCTAC-3' \\
Reverse & 5'-CTCTGTTCCTGGCTTTTATTGA-3' \\
3-actin & \\
Forward & 5'- TTGCCGACAGGATGCAGAA-3' \\
Reverse & 5'-GCCGATCCACACGGAGTACT-3' \\
\hline
\end{tabular}

NKP44, natural-killer protein 44; NKG2D, natural-killer group 2, member $\mathrm{D}$.

CD158b (11), and the activating receptors were identified as NKG2D, DNAM-1 and NKp44 $(12,13)$. The CD107a expression was measured in $\mathrm{CD}^{-} 6^{+}$and $\mathrm{CD}^{-} 6^{-} \mathrm{NK}$ cells. Stained cells were also analyzed using a flow cytometer and associated software as aforementioned.

Isolation and purification of target NK lymphocytes. A total of $10 \mathrm{ml}$ fresh human peripheral blood was obtained from patients with MDS and from normal controls. PBMNCs were 
A

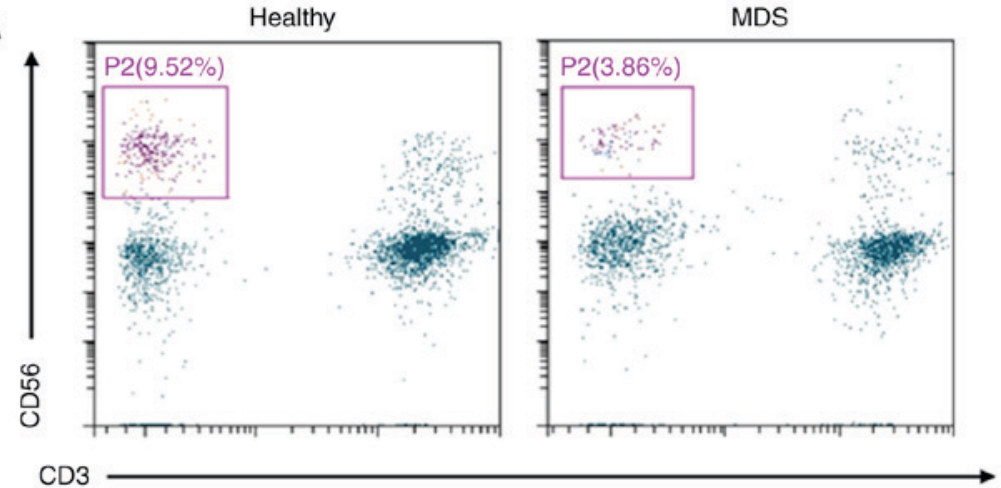

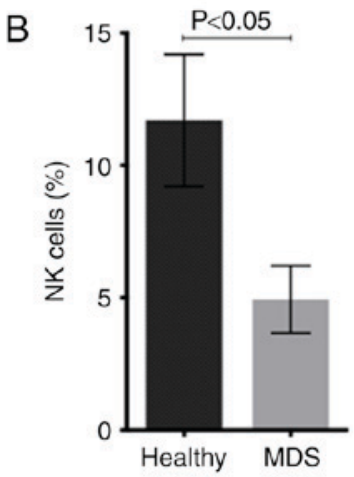

Figure 1. NK cells in different healthy controls and MDS. (A) Representative flow cytometry gating for NK cells (CD3-CD56 ${ }^{+}$). (B) The percentages of NK cells in healthy controls and patients with MDS. NK, natural killer; CD, cluster of differentiation; MDS, myelodysplastic syndromes.

isolated by density gradient centrifugation using Ficoll-Paque Plus solution (GE Healthcare, Chicago, USA) at $400 \mathrm{x} g$ for $20 \mathrm{~min}$ at room temperature. The purified NK cells were subsequently obtained using an NK Cell Isolation kit (Miltenyi Biotech, Bergisch Gladbach, Germany). Isolated PBMNCs were mixed with NK Cell Biotin-Antibody Cocktail from the kit (cat. no. 130092657) and incubated for 5 min at $4^{\circ} \mathrm{C}$ followed by NK Cell MicroBead Cocktail from the kit (cat. no. 130092657) and subsequent magnetic cell separation. Following detection using a multi-parametric flow cytometer (BD Biosciences) and analysis using Cell Quest software (version 3.1; BD Biosciences), the purity of $\mathrm{CD} 3{ }^{-} \mathrm{CD} 56^{+} \mathrm{NK}$ cells was $90-99 \%$.

Reverse transcription-quantitative polymerase chain reaction $(R T-q P C R)$. Total RNA in previously purified NK cells was extracted using TRIzol reagent (Invitrogen; Thermo Fisher Scientific, Inc., Waltham, USA) and $1 \mu \mathrm{g}$ RNA was reversed transcribed using a TIANScript RT kit (Tiangen Biotech Co., Ltd., Beijing, China). The thermocycler conditions were; $50 \mathrm{~min}$ at $42^{\circ} \mathrm{C}$, followed by $5 \mathrm{~min}$ at $95^{\circ} \mathrm{C}$. The sequences of primers specific for perforin, granzyme B, NKG2D, NKP44 and $\beta$-actin, which were designed and synthesized by Sangon Biotech Co., Ltd. (Shanghai, China), are listed in Table II.

qPCR was performed on a Bio-Rad iQ5 Real-Time system (Bio-Rad Laboratories, Inc., USA) using a SYBR Green kit (Tiangen Biotech Co., Ltd.). The thermocycler conditions were as follows: Denaturation for $2 \mathrm{~min}$ at $94^{\circ} \mathrm{C}$, then 40 cycles of $15 \mathrm{sec}$ at $58^{\circ} \mathrm{C}$ for elongation followed by the annealing step of $40 \mathrm{sec}$ at $72^{\circ} \mathrm{C}$. $\beta$-actin was used as an internal reference gene for standardizing the expression of targeted mRNA. All reactions were performed in triplicate and single outliers, with values $>5 \mathrm{Ct}$ compared with the average of the remaining two $\mathrm{Ct}$ values discarded. The gene expression ratio was calculated using the $2^{-\Delta \Delta \mathrm{Ct}}$ method (14).

Statistical analysis. Statistical analysis was performed using GraphPad Prism software (version 5.0.1; GraphPad Software, Inc., La Jolla, CA, USA). Quantitative data were presented as mean \pm standard deviation. The differences in the distribution of continuous variables between two categories were analyzed using Student's t-test for normally distribution data and Mann-Whitney test for non-parametric data. For data involving three or more groups, the Kruskal-Wallis test was used. All reported P-values were two-sided and $\mathrm{P}<0.05$ was considered to indicate a statistically significant difference.

\section{Results}

NK cell subsets and NKT cells in MDS cases compared with non-MDS cases. The number of NK cells $\left(\mathrm{CD}^{-} \mathrm{CD}^{-} 6^{+}\right)$in distinct subgroups of diseases was measured. The percentage of NK cells in peripheral blood lymphocytes was $4.94 \pm 1.28 \%$ in patients with MDS and $11.69 \pm 2.49 \%$ in healthy controls (Fig. 1). Subsequently, the $\mathrm{CD} 16^{+} \mathrm{NK}$ cell subset and the NKT cells $\left(\mathrm{CD}^{2} 6^{+} \mathrm{CD}^{+}\right)$were separated into different disease subgroups, and flow cytometry indicated that the percentage of peripheral blood $\mathrm{CD} 16^{+} \mathrm{NK}$ cells was significantly decreased in patients with MDS and AML compared with that in healthy donors (Fig. 2A). The percentage of $\mathrm{CD}^{+} 6^{+} \mathrm{NK}$ cells in peripheral blood lymphocytes was $15.20 \pm 6.41 \%$ in patients with MDS, $9.97 \pm 4.26 \%$ in patients with AML and $20.14 \pm 3.61 \%$ in healthy controls. The percentage of $\mathrm{CD} 16^{+} \mathrm{NK}$ cells in patients with MDS was significantly decreased compared with that in healthy controls $(\mathrm{P}<0.001)$ and the percentage of $\mathrm{CD} 16^{+} \mathrm{NK}$ cells in patients with $\mathrm{AML}$ was significantly decreased compared with that in patients with MDS $(\mathrm{P}<0.05)$. The median percentage of NKT cells was $2.36 \%$ in patients with MDS, $4.31 \%$ in patients with AML and $2.14 \%$ in healthy controls. There were no significant differences between the percentage of NKT cells in patients with MDS/AML and healthy donors (Fig. 2B).

Subsequently, the distinct subtypes of mature CD56 ${ }^{\mathrm{dim}} \mathrm{NK}$ cells and less mature CD56 $6^{\text {bright }}$ cells were investigated. The percentage of CD56 ${ }^{\mathrm{dim}}$ cells was $13.92 \pm 6.37 \%$ in patients with MDS, $9.03 \pm 4.35 \%$ in patients with AML and $22.95 \pm 3.55 \%$ in healthy controls. Consistent with the results in NK cells, the percentage of CD56 ${ }^{\mathrm{dim}}$ cells in patients with MDS was significantly decreased compared with that in healthy controls $(\mathrm{P}<0.001)$, and the percentage of CD56 ${ }^{\mathrm{dim}}$ cells in patients with AML was significantly decreased compared with that in patients with MDS ( $\mathrm{P}<0.05$; Fig. $2 \mathrm{C}$ ). The median percentage of CD56 $6^{\text {bright }}$ cells was $0.59 \%$ in patients with MDS, $0.42 \%$ in patients with AML and $0.39 \%$ in healthy controls; no statistical difference was observed between patients with MDS/AML and healthy donors (Fig. 2D). 
A

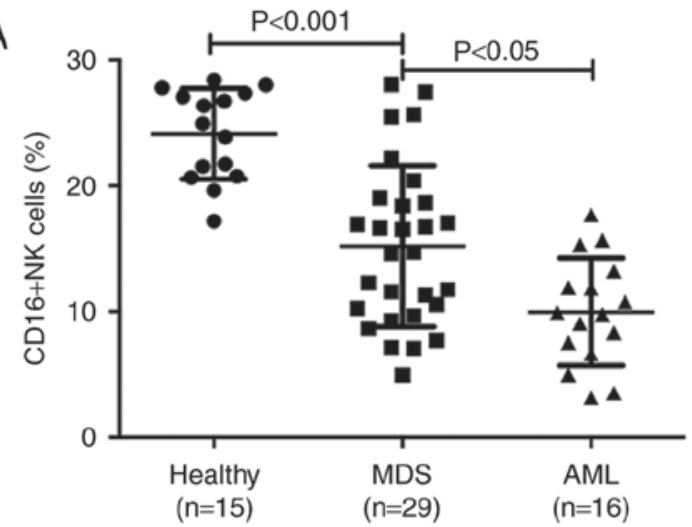

C

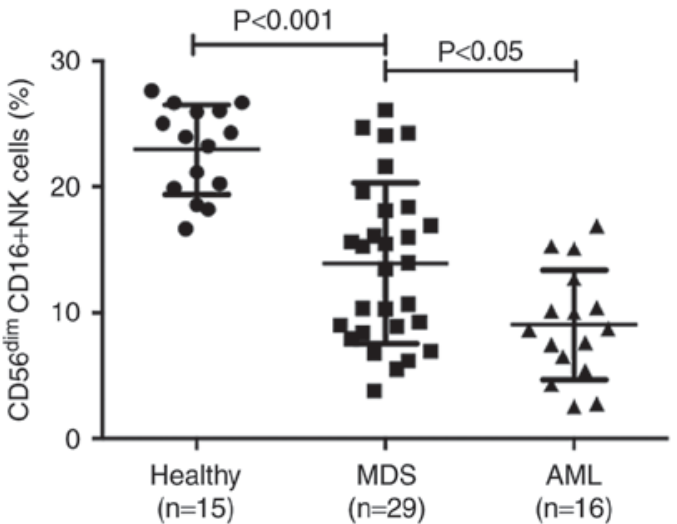

B

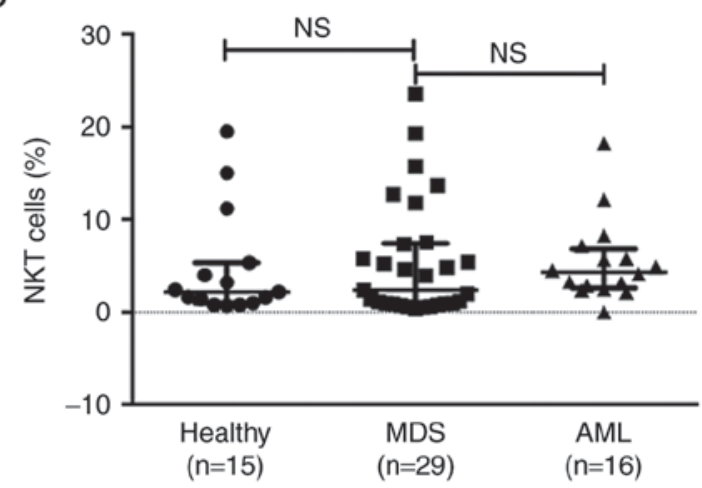

D

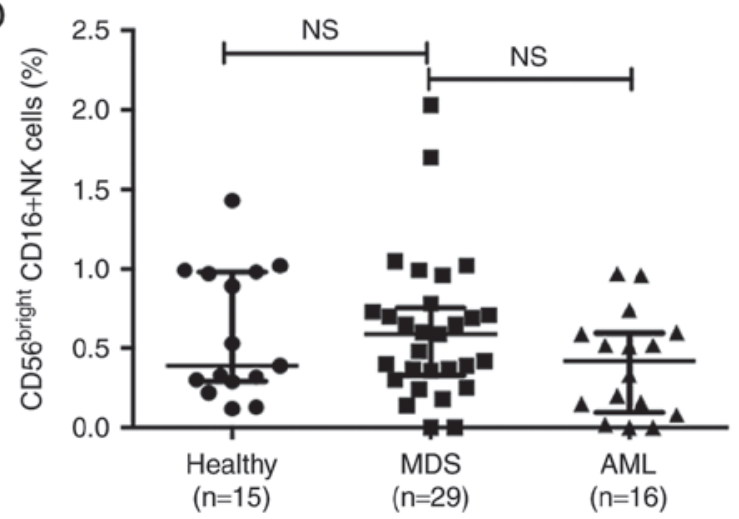

Figure 2. CD16 ${ }^{+} \mathrm{NK}$ cells and NKT cells in different subgroups of diseases. (A) The percentages of CD16 ${ }^{+} \mathrm{NK}$ cells $\left(\mathrm{CD} 3{ }^{-} \mathrm{CD} 56^{+} \mathrm{CD} 16^{+}\right)$in healthy control, $\mathrm{MDS}^{-}$ and AML groups. (B) The percentages of NKT cells $\left(\mathrm{CD} 56^{+} \mathrm{CD} 3^{+}\right)$in healthy control, MDS and AML groups. (C) Difference in CD56 ${ }^{\text {dim }}$ cells in healthy control, MDS and AML groups. (D) Level of CD56 ${ }^{\text {bright }}$ cells in healthy control, MDS and AML groups. NK cell deficiency is associated with high-risk subgroups. CD, cluster of differentiation; NK, natural killer; NKT, NK-like T; MDS, myelodysplastic syndromes; AML, acute myeloid leukemia; NS, not significant.

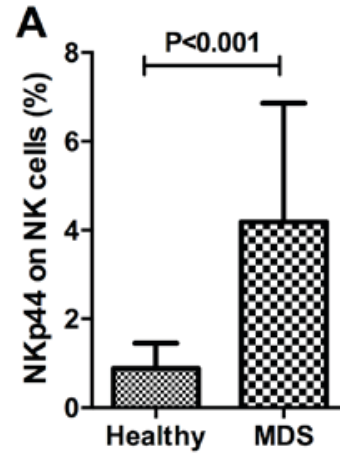

$c$

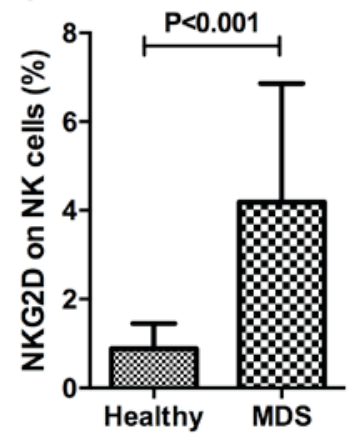

B

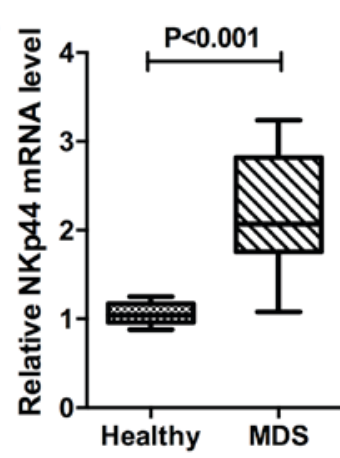

D

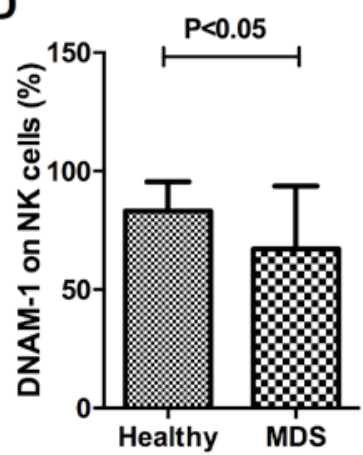

Figure 3. NKp44, NKG2D and DNAM-1 in patients with MDS and healthy controls. (A) The expression of NKp44 on NK cells in patients with MDS and healthy controls. (B) The relative mRNA expression level of NKp44 in purified target NK lymphocytes. (C) The percentage of NKG2D on NK cells of patients with MDS and healthy controls. (D) The expression of DNAM-1 on NK cells in MDS patients and healthy controls. Inhibitory receptors on NK cells were decreased in MDS patients compared with healthy controls. NK, natural killer; NKG2D, NK group 2, member D; DNAM-1, cluster of differentiation 226; MDS, myelodysplastic syndromes. 
A

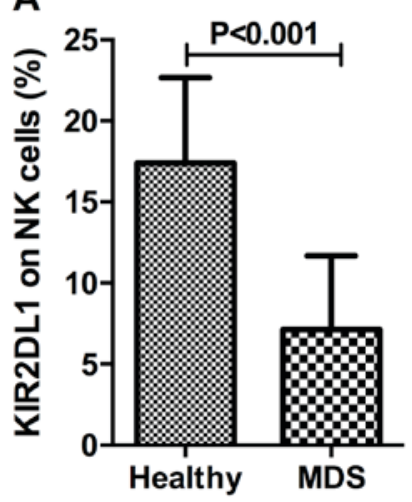

B

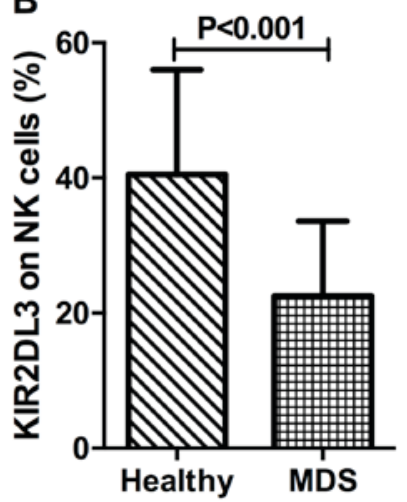

Figure 4. KIR2DL1 (CD158a) and KIR2DL3 (CD158b) in NK cells. (A) The expression of KIR2DL1 on NK cells in patients with MDS and healthy controls. (B) The percentage of KIR2DL3 on NK cells of patients with MDS and healthy controls. Cytotoxic deficiency of NK cells was revealed in patients with MDS. KIR2DL1, killer cell immunoglobulin-like receptor 2DL1; CD, cluster of differentiation; NK, natural killer; MDS, myelodysplastic syndromes.

The association between NK cell deficiency and specific disease subgroups (data not shown), as defined by the International Prognostic Scoring System (10), was evaluated. In the present study, patients in the low risk group were $20 \%$, intermediate-1 group were $23 \%$, intermediate- 2 group were $37 \%$ and high risk group were $20 \%$. The percentage of $\mathrm{CD}^{+} 6^{+} \mathrm{NK}$ cells was lower in the high-risk MDS group $(12.19 \pm 4.56 \%)$ than in the low-risk group $(17.20 \pm 5.67 \%$; $\mathrm{P}<0.05)$.

Activating receptors and adhesion receptors on NK cells in patients with MDS. The present study investigated NKp44 protein and mRNA expression in the natural cytotoxicity receptors (NCR). The expression percentage of NKp44 on $\mathrm{CD}^{+} 6^{+} \mathrm{NK}$ cells in peripheral blood was $4.18 \pm 2.68 \%$ in patients with MDS and $0.89 \pm 0.56 \%$ in healthy controls, which was significantly different $(\mathrm{P}<0.001)$. In $\mathrm{CD} 16^{+} \mathrm{NK}$ cells, RNA expression of NKp44 in MDS samples was compared with that in controls. The relative expression of NKp44 in purified target NK lymphocytes was $2.20 \pm 0.63 \%$ in patients with MDS and $1.05 \pm 0.12 \%$ in healthy controls, which was consistent with the results of protein expression demonstrated a significant difference $(\mathrm{P}<0.001)$. Taken together, these results indicated that NKp44 expression in the NK cells $\left(\mathrm{CD}^{-} \mathrm{CD} 56^{+} \mathrm{CD} 16^{+}\right)$of patients with MDS was significantly increased compared with that in healthy donors (Fig. 3A and B).

The present study also measured other stimulatory signals, including NKG2D and DNAM-1. The percentage of NKG2D in total NK cells of healthy controls and patients with MDS were $0.89 \pm 0.56$ and $4.18 \pm 2.68 \%$, respectively $(\mathrm{P}<0.001$; Fig. 3C). Glycoprotein DNAM-1 expression on NK cells in peripheral blood was $67.17 \pm 26.55 \%$ in patients with MDS and $83.11 \pm 12.31 \%$ in healthy controls, a difference that was statistically significant $(\mathrm{P}<0.05$; Fig. 3D). On the surface of NK cells, expression of DNAM-1, a protein that mediates cellular adhesion (15-16), was decreased in MDS, whereas expression of NKG2D, which mediates lysis of certain tumor cells (17-18), was increased, compared with the healthy control.

For the identification of inhibitory NK cell receptors, the present study investigated two killer cell immunoglobulin-like receptors, CD158a (also known as KIR2DL1) and CD158b (also known as KIR2DL3). The percentage of KIR2DL1 in NK cells of patients with MDS and healthy controls was $7.12 \pm 4.55$ and $17.39 \pm 5.27 \%$, respectively $(\mathrm{P}<0.001$; Fig. $4 \mathrm{~A})$. The percentage of NK cells expressing KIR2DL3 was $22.55 \pm 11.05 \%$ in patients with MDS and $40.51 \pm 15.50 \%$ in healthy controls, which demonstrated a statistically significant difference $(\mathrm{P}<0.001$; Fig. 4B).

To determine the cytotoxic function of NK cells in patients with MDS, the expression percentage and relative mRNA level of perforin and granzyme B on target NK cells was evaluated. The expression of CD107a was also evaluated in different subsets of NK cells.

The percentage of perforin-expressing NK cells in the MDS group was $25.67 \pm 12.71 \%$, which was significantly decreased compared with the healthy control group (65.33 $\pm 13.65 \%$; $\mathrm{P}<0.001$; Fig. 5A). In the isolated pure NK cells, the relative mRNA expression levels of perforin in the MDS and healthy control samples were $0.42 \pm 0.12 \%$ and $1.06 \pm 0.09 \%$, respectively, a difference that was consistent with the protein expression results, as well as demonstrating significance $(\mathrm{P}<0.001 ;$ Fig. 5B). The percentage of granzyme B on target NK cells from the MDS group was $24.30 \pm 15.36 \%$, which was significantly decreased compared with that in the healthy control group $(86.52 \pm 7.46 \%$; $\mathrm{P}<0.001$; Fig. 5C). The relative mRNA expression of granzyme B in the MDS and healthy control samples was $0.31 \pm 0.10$ and $1.06 \pm 0.11 \%$, respectively, a difference that was statistically significant $(\mathrm{P}<0.001$; Fig. 5D). These results indicated that patients with MDS were deficient in perforin and granzyme $\mathrm{B}$ at the protein and the mRNA level. The differences in CD107a expression on $\mathrm{CD}^{+} 6^{+} \mathrm{NK}$ and $\mathrm{CD} 16-\mathrm{NK}$ subsets demonstrated ADCC-mediated NK activity in MDS patients. The percentage of $\mathrm{CD} 16^{+} \mathrm{NK}$ expressing CD107a was increased in patients with MDS compared with that in controls $(\mathrm{P}<0.05$; Fig. 5E). Conversely, the expression of CD107a was decreased in CD16-NK subsets of MDS compared with the normal control $(\mathrm{P}<0.05$; Fig. 5F).

\section{Discussion}

NK cells are lymphocytes that are able to kill any target that lacks self-major histocompatibility complex (MHC) class I molecules, also known as 'missing self', by mediating 
A

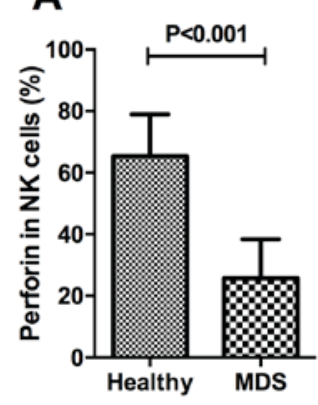

D

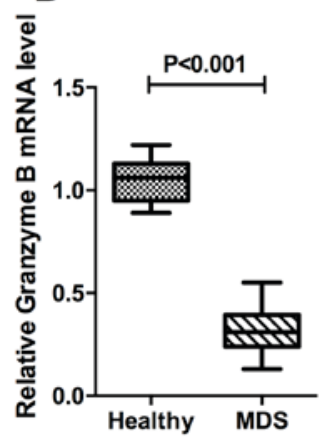

B

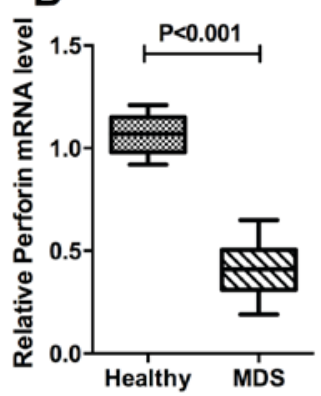

$\mathbf{E}$

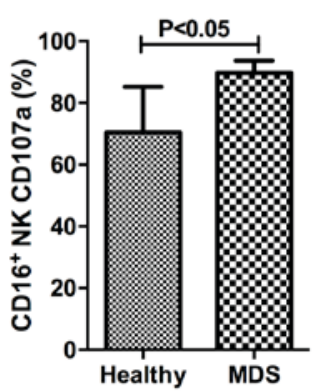

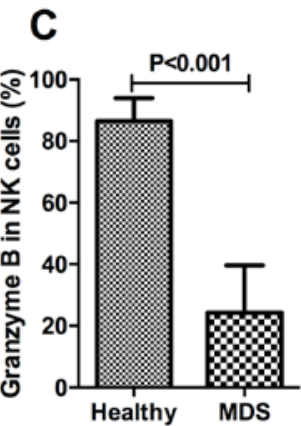

$\mathbf{F}$

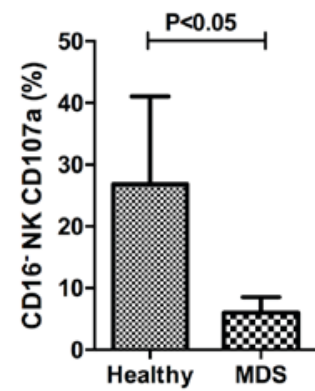

Figure 5. Perforin, granzyme B and CD107a expression on target NK cells. (A) The expression of perforin in NK cells in patients with MDS and healthy controls. (B) The relative mRNA expression level of perforin in purified target NK lymphocytes. (C) The expression of granzyme B in NK cells in patients with MDS and controls. (D) The relative mRNA expression level of granzyme B in purified target NK lymphocytes. (E) The expression of CD107a on CD16 ${ }^{+} \mathrm{NK}$ cells in patients with MDS and healthy controls. (F) CD107a on CD16-NK cells in patients with MDS and healthy controls. CD, cluster of differentiation; NK, natural killer; MDS, myelodysplastic syndromes.

lysis of certain tumor cells and virus-infected cells without previous activation (5). Based on flow cytometric analysis, the traditional phenotype used to define human NK cells was the expression of CD56 and the absence of CD3, excluding $\mathrm{T}$ cells within the lymphocyte gate $(5,6,11)$. In the present study, the $\mathrm{CD} 3{ }^{-} \mathrm{CD} 56^{+} \mathrm{NK}$ cell population in peripheral blood lymphocytes was decreased in patients with MDS compared with that in healthy controls. Furthermore, CD16 was also used to identify NK cells that may lead to ADCC, which is a dominant component of effective antitumor activity (19). Additionally, the proportion of $\mathrm{CD} 3{ }^{-} \mathrm{CD} 56^{+} \mathrm{CD} 16^{+}$-expressing NK cells in the peripheral blood was decreased in patients with MDS or AML compared with that in healthy donors, and the percentage of $\mathrm{CD} 16^{+} \mathrm{NK}$ cells in patients with AML was decreased compared with that in patients with MDS. As $\mathrm{CD}_{16}{ }^{+} \mathrm{NK}$ cells are important in immunological tumor surveillance $(18,20)$, a lack of $\mathrm{CD}^{6} 6^{+} \mathrm{NK}$ cells in patients with MDS or AML may explain their increased tumor burden. The target recognition and host defense functions of NK and cytolytic T cells have suggested that they may evolve from a common ancestral cytolytic effector cell; however, the proportion of $\mathrm{CD} 3{ }^{+} \mathrm{CD} 56^{+}$-expressing NKT cells did not differ significantly between patients with MDS or AML and healthy donors, in the present study. T-cells with expression of CD56 and/or CD16/57 were defined as NKT cells in previous study, but only the $\mathrm{CD}^{+} \mathrm{CD}^{+} 6^{+}$-expressing cells were included in our study. The specific gating strategy utilized in the present study may explain why the frequency of NKT observed in patients with MDS was decreased competed with that in previously published data (21). Therefore, NK cells displaying cytolytic capacity against target cells were further investigated. Human NK cells may be distinguished by CD56 surface expression density; high expression of CD56 subsets may produce significantly increased levels of cytokines in response to activation, however may exhibit weaker target function $(12,22)$. The majority of circulating NK cells are CD56 $6^{\mathrm{dim}}$ and express high levels of CD16, which exhibit a decreased ability to produce cytokines compared with the CD56 $6^{\text {bright }} \mathrm{NK}$ cells (22), and improved ability to effectively mediate ADCC and natural cytotoxicity $(5,19)$. The results of the present study demonstrated that an increased number of $\mathrm{CD}^{+} 6^{+} \mathrm{NK}$ cells were $\mathrm{CD} 56^{\mathrm{dim}}$ and that the percentages of $\mathrm{CD} 56^{\mathrm{dim}} \mathrm{CD} 16^{+} \mathrm{NK}$ cells in the peripheral blood were decreased in patients with MDS, compared with healthy control. Therefore, we hypothesized that the number of $\mathrm{CD}^{2} 6^{\mathrm{dim}} \mathrm{CD} 16^{+} \mathrm{NK}$ cells was too limited for them to be able to recognize the cancerous cells, thereby resulting in the ineffective hematopoiesis observed in MDS.

NK cells exhibit a dynamic balance of several distinct families of activating and inhibitory signals that engage potential target cell recognition $(5,23-25)$. In humans, the major receptors responsible for tumor cell recognition are NKp46, NKp30, NKp44, DNAM1 and NKG2D (25). The NCR family consists of NKp46, NKp30 and NKp44. NKp46 is a popular maker for NK cells, and resting and activated NK cells express NKp30 and NKp46, whereas NKp44 is limited to IL-2-activated NK cells $(5,12)$. The present study observed an increased expression of NKp44 in CD16 ${ }^{+} \mathrm{NK}$ cells of patients with MDS patients at the protein and RNA level compared with the healthy donors, indicating that an increased number of NK cells favored the activated condition in MDS. The present study also measured other stimulatory signals, including NKG2D and DNAM-1. 
NKG2D, also known as CD314, is characterized by the presence of a calcium-dependent lectin domain that is preferentially expressed in NK cells, and binds to ligands, including MHC class I chain-related A and B proteins, which may result in the activation of NK cells $(17,23)$. DNAM-1 (also known as $\mathrm{CD} 226)$ is a member of the immunoglobulin ( $\mathrm{Ig}$ )-superfamily containing two Ig-like V-set domains and is categorized as a cellular adhesion receptor of NK cells $(16,25)$. In the present study, the percentage of NKG2D expression in total NK cells of the MDS group was significantly increased compared with that of the healthy control group, and glycoprotein DNAM-1 expression on NK cells in the peripheral blood was decreased in patients with MDS compared with that in healthy controls. Killer cell Ig-like receptors (KIRs) are glycoproteins classified by the number of extracellular Ig domains and by whether they possess a long or short cytoplasmic domain; KIRs with a long cytoplasmic domain containing an immune tyrosine-based inhibitory motif (ITIM) interact with MHC class I as inhibitory signals upon ligand binding (23). With regards to inhibitory receptors expressed on human peripheral blood NK cells, the percentage of KIR2DL1 and KIR2DL3 in NK cells of the MDS group was decreased compared with that of the healthy control group. In conclusion, the coordinated expression of NCRs, NKG2D and inhibitory signals, including KIRs, may trigger the process of tumor cell lysis in MDS while cellular adhesion may be the underlying biological mechanism.

In NK cell effector signaling pathways, activating receptors initiate protein tyrosine kinase-dependent and DAP10 signaling pathways. Inhibitory receptors characterized by ITIMs antagonize activating signaling pathways through protein tyrosine phosphatases. Therefore, expression of certain receptors may trigger cytolytic programs and cytokine or chemokine secretion through these pathways (24). In the present study, as a result of effector signaling pathways of NK cells, the expression percentage and relative mRNA level of perforin and granzyme $\mathrm{B}$ on target NK cells were downregulated in patients with MDS. The increased expression of CD107a on CD16 ${ }^{+} \mathrm{NK}$ cells demonstrated ADCC-mediated NK activity in patients with MDS, whereas the decreased CD107a expression on CD16-NK cells revealed the inability of degranulation in patients with MDS, compared with the healthy control. As a result of the lack of key effector molecule for cytolysis, the cancerous cells in patients with MDS may fail to undergo lysis, resulting in progression to AML.

In conclusion, $\mathrm{CD}_{16}{ }^{+}$-expressing $\mathrm{NK}$ cells and subset CD56 $6^{\text {dim }} \mathrm{NK}$ cells were decreased in the peripheral blood of patients with MDS, compared with healthy controls. Altered expression of activating receptors and inhibitory signals on NK cell effector signaling pathways may trigger the process of tumor cell lysis in patients with MDS; however, the weak cellular adhesion and decreased cytotoxicity of NK cells may lead to ineffective antitumor activity in MDS. The conclusion of the present study that NK cell function is decreased in patients with MDS is limited by the lack of functional assays. Therefore, it is important that future studies explore functional assays, including cytotoxicity against K562 in NK cells from patients with MDS. Future analysis comprising larger MDS cohorts and different stages of MDS is required. The observations of the present study indicated the function of NK cells as immunological determinants in MDS and may allow the development of NK cell-based immunotherapy or newly-validated immunomodulatory agents for the treatment of patients with MDS $(19,26)$.

\section{Acknowledgements}

Not applicable.

\section{Funding}

The present study was supported by grants from the National Natural Science Foundation of China (grant nos. 81570111 and 81400085) and the Foundation of Tianjin Medical University (grant no. 2012KYQ15).

\section{Availability of data and materials}

The datasets used and/or analyzed during the current study are available from the corresponding author on reasonable request.

\section{Authors' contributions}

All authors have read and approved the final manuscript. HM, JS, SD, LL and HL performed the experiments. WZ, RF and ZS designed the study. XX performed the FCM experiments of CD107a, analyzed and interpreted the data. HW contributed to the conception of the work, interpretation of the data and revision for important intellectual content. XX and HW wrote the paper.

\section{Ethics approval and consent to participate}

The present study was approved by the Tianjin Medical University Institutional Review Board (Tianjin, China). Patients consented to participate in this study.

\section{Consent for publication}

All patients provided written informed consent in accordance with the Declaration of Helsinki.

\section{Competing interests}

The authors declare that they have no competing interests.

\section{Reference}

1. Adès L, Itzykson R and Fenaux P: Myelodysplastic syndromes. Lancet 383: 2239-2252, 2014.

2. Tefferi A and Vardiman JW: Myelodysplastic syndromes. N Engl J Med 361: 1872-1885, 2009.

3. Alfinito F, Sica M, Luciano L, Della Pepa R, Palladino C, Ferrara I, Giani U, Ruggiero G and Terrazzano G: Immune dysregulation and dyserythropoiesis in the myelodysplastic syndromes. Br J Haematol 148: 90-98, 2010.

4. Kordasti SY, Ingram W, Hayden J, Darling D, Barber L, Afzali B, Lombardi G, Wlodarski MW, Maciejewski JP, Farzaneh F and Mufti GJ: CD4+CD25high Foxp3+ regulatory T cells in myelodysplastic syndrome (MDS). Blood 110: 847-850, 2007.

5. Caligiuri MA: Human natural killer cells. Blood 112: 461-469, 2008.

6. Hejazi M, Manser AR, Frobel J, Kündgen A, Zhao X Schönberg K, Germing U, Haas R, Gattermann N and Uhrberg M: Impaired cytotoxicity associated with defective natural killer cell differentiation in myelodysplastic syndromes. Haematologica 100: 643-652, 2015. 
7. Chamuleau ME, Westers TM, van Dreunen L, Groenland J, Zevenbergen A, Eeltink CM, Ossenkoppele GJ and van de Loosdrecht AA: Immune mediated autologous cytotoxicity against hematopoietic precursor cells in patients with myelodysplastic syndrome. Haematologica 94: 496-506, 2009.

8. Epling-Burnette PK, Bai F, Painter JS, Rollison DE, Salih HR, Krusch M, Zou J, Ku E, Zhong B, Boulware D, et al: Reduced natural killer (NK) function associated with high-risk myelodysplastic syndrome (MDS) and reduced expression of activating NK receptors. Blood 109: 4816-4824, 2007.

9. Vardiman JW, Thiele J, Arber DA, Brunning RD, Borowitz MJ, Porwit A, Harris NL, Le Beau MM, Hellström-Lindberg E, Tefferi A and Bloomfield CD: The 2008 revision of the World Health Organization (WHO) classification of myeloid neoplasms and acute leukemia: Rationale and important changes. Blood 114: 937-951, 2009.

10. Greenberg P, Cox C, LeBeau MM, Fenaux P, Morel P, Sanz G, Sanz M, Vallespi T, Hamblin T, Oscier D, et al: International scoring system for evaluating prognosis in myelodysplastic syndromes. Blood 89: 2079-2088, 1997.

11. Kogure T, Fujinaga H, Niizawa A, Hai LX, Shimada Y, Ochiai H and Terasawa K: Killer-cell inhibitory receptors, CD158a/b, are upregulated by interleukin-2, but not interferon-gamma or interleukin-4. Mediators Inflamm 8: 313-318, 1999.

12. El-Sherbiny YM, Meade JL, Holmes TD, McGonagle D, Mackie SL, Morgan AW, Cook G, Feyler S, Richards SJ, Davies FE, et al: The requirement for DNAM-1, NKG2D and NKp46 in the natural killer cell-mediated killing of myeloma cells. Cancer Res 67: 8444-8449, 2007.

13. Baychelier F, Sennepin A, Ermonval M, Dorgham K, Debré P and Vieillard V: Identification of a cellular ligand for the natural cytotoxicity receptor NKp44. Blood 122: 2935-2942, 2013.

14. Livak KJ and Schmittgen TD: Analysis of relative gene expression data using real-time quantitative PCR and the 2(-Delta Delta C(T)) method. Methods 25: 402-408, 2001.

15. Shibuya A, Campbell D, Hannum C, Yssel H, Franz-Bacon K, McClanahan T, Kitamura T, Nicholl J, Sutherland GR, Lanier LL and Phillips JH: DNAM-1, a novel adhesion molecule involved in the cytolytic function of $t$ lymphocytes. Immunity 4: 573-581, 1996.

16. Carlsten M, Baumann BC, Simonsson M, Jädersten M, Forsblom AM, Hammarstedt C, Bryceson YT, Ljunggren HG, Hellström-Lindberg E and Malmberg KJ: Reduced DNAM-1 expression on bone marrow NK cells associated with impaired killing of CD34+ blasts in myelodysplastic syndrome. Leukemia 24: 1607-1616, 2010.
17. Schlegel P, Ditthard K, Lang P, Mezger M, Michaelis S, Handgretinger R and Pfeiffer M: NKG2D signaling leads to NK cell mediated lysis of childhood AML. J Immunol Res 2015: 473175, 2015

18. Konjević G, Mirjacić Martinović K, Jurisić V, Babović N and Spuzić I: Biomarkers of suppressed natural killer (NK) cell function in metastatic melanoma: decreased NKG2D and increased CD158a receptors on CD3-CD16+ NK cells. Biomarkers 14: 258-270, 2009.

19. Battella S, Cox MC, Santoni A and Palmieri G: Natural killer (NK) cells and anti-tumor therapeutic mAb: Unexplored interactions. J Leukoc Biol 99: 87-96, 2016.

20. Ebert LM, Meuter S and Moser B: Homing and function of human skin gammadelta T cells and NK cells: Relevance for tumor surveillance. J Immunol 176: 4331-4336, 2006.

21. Aggarwal N, Swerdlow SH, TenEyck SP, Boyiadzis M and Felgar RE: Natural killer cell (NK) subsets and NK-like T-cell populations in acute myeloid leukemias and myelodysplastic syndromes. Cytometry B Clin Cytom 90: 349-357, 2016.

22. Cooper MA, Fehniger TA, Turner SC, Chen KS, Ghaheri BA, Ghayur T, Carson WE and Caligiuri MA: Human natural killer cells: A unique innate immunoregulatory role for the CD56 (bright) subset. Blood 97: 3146-3151, 2001.

23. Bryceson YT, March ME, Ljunggren HG and Long EO Activation, coactivation, and costimulation of resting human natural killer cells. Immunol Rev 214: 73-91, 2006.

24. Vivier E, Nunès JA and Vély F: Natural killer cell signaling pathways. Science 306: 1517-1519, 2004

25. Vivier E, Raulet DH, Moretta A, Caligiuri MA, Zitvogel L, Lanier LL, Yokoyama WM and Ugolini S: Innate or adaptive immunity? The example of natural killer cells. Science 331: 44-49, 2011.

26. Bachanova V and Miller JS: NK cells in therapy of cancer. Crit Rev Oncog 19: 133-141, 2014.

(c) (i) (9) This work is licensed under a Creative Commons Attribution 4.0 International (CC BY-NC 4.0) License 